\section{Collection and analysis of post mortem inspection outcomes (liver lesions) from different cattle slaughtering plants located in Northern and Southern Italy}

\author{
Simone Stella, ${ }^{1}$ Erica Tirloni, ${ }^{1}$ \\ Cristian Bernardi, ${ }^{1}$ Greta Acerbis, ${ }^{1}$ \\ Teresa Manginelli ${ }^{2}$
}

${ }^{1}$ Department of Veterinary Medicine and Animal Sciences, University of Milan;

${ }^{2}$ Department of Prevention, Local

Health Authority of the Province of

Bari, Italy

\begin{abstract}
The study evaluated the outcomes of
\end{abstract} cattle liver postmortem examination (64,766 animals) obtained from three slaughterhouses (two located in Lombardy, Northern Italy, and one in Puglia, Southern Italy) through the period 2016-2020. The frequency of specific lesions determining liver condemnation was calculated and the influence of several factors (animal age/category, geographical area, season, plant) was considered. A mean prevalence of $8 \%$ was observed, with a significant difference among the plants (range 6.4-12.8\%). A significant difference was observed among the animal categories and age classes, with higher condemnation rates in animals aged more than 30 months (mainly cows). Steatosis was the most frequent lesion observed in cows (about half of the total), whereas liver abscesses were the most diffused in younger animals (half of the total in young bulls). Other frequently observed lesions were distomatosis and perihepatitis. A different pattern was observed between the two geographical areas, with a higher prevalence of steatosis in Lombardy (mainly intensive dairy farming), and of distomatosis in Puglia (animals mainly grazed on pasture). The season influenced the prevalence of lesions, and especially of steatosis (higher in summer). A different lesion prevalence was also observed between the two plants on similar animal populations, suggesting a difference in the notification and classification procedure among the plants. This study highlights the importance of a proper sharing procedure of the information obtained from the post mortem inspection in order to facilitate an optimal use of Food Chain Information and a useful feedback for farmers.

\section{Introduction}

Liver is one of the most important organs submitted to veterinary post mortem inspection during cattle slaughtering, as it is the main offal intended for human consumption, but after all it is of particular interest as a "filter" organ, receiving blood from the digestive tract via the portal vein, thus indicating a potential dissemination of pathogenic bacteria or parasites. Moreover, owing to its major metabolic role, its condition can give a picture of the general state of the whole carcass. The economic loss due to liver lesions may be significant: several studies observed a correlation between the presence of liver lesions and systemic dysfunctions, leading to a slower weight increase, a lower final weight (especially in feedlot cattle) and decreased milk production and fertility in cows (Khan et al., 2009; Brown et al., 2010; Schweizer et al., 2015; Montanholi et al., 2017).

The main lesions causing the condemnation of the liver and, in some cases, of the whole carcass and that can be revealed during the gross post mortem inspection of cattle are: circulation disturbances (e.g. congestion); degeneration of liver tissue, the most frequent being steatosis ("fatty liver"), often caused by post partum lipomobilization in milking cows; abscesses, due to the diffusion of pyogenic bacteria from the stomachs or gut, especially in feedlot cattle (due to a lack of fiber in the feed), or to the penetration of metal pieces (traumatic reticuloperitonitis); parasitic diseases, typically detected in animals grazed on pastures: the most frequently detected are caused by cestodes (hydatid cyst of Echinococcus granulosus, Cysticercus tenuicollis from Taenia hydatigena) and trematodes (Fasciola hepatica, Dicrocoelium dendriticum); fibrosis/cirrhosis, that represent a sequela of previous lesions, and can affect the functionality of the liver. Other lesions can be very frequent (e.g. melanosis in the liver of calves, telangiectasis in cows, perihepatitis with adhesion fimbriae), but are not generally linked to the state of the carcass, and their significance is scarce. Other lesions of great inspective importance (e.g. nodules caused by tuberculosis or actinobacillosis) are rare.

The current legislation (EU Reg. 627/2019) prescribes the official veterinarian to act only a visual inspection of bovine liver in absence of particular risk elements, but this procedure still allows to detect the most important lesions (Stärk et al., 2014). It has to be noted that gross post mortem inspection can reveal the presence of diseases or dysfunctions that are not detectable at an ante mortem inspection (Dupuy et al.,
Correspondence: Simone Stella, Department of Veterinary Medicine and Animal Sciences, University of Milan, Via dell'Università 6, IT-26900, Lodi, Italy.

Tel:. +39.02.50334311

E-mail: simone.stella@unimi.it

Key words: Liver lesions, Post mortem inspection, Steatosis, Abscesses, Distomatosis.

Contributions: The authors contributed equally.

Conflict of interest: The authors declare no conflict of interest.

Funding: None.

Received for publication: 12 August 2021.

Accepted for publication: 10 January 2022.

This work is licensed under a Creative Commons Attribution-NonCommercial 4.0 International License (CC BY-NC 4.0).

(C) Copyright: the Author(s), 2022

Licensee PAGEPress, Italy

Italian Journal of Food Safety 2022; 11:10035 doi:10.4081/ijfs.2022.10035

2013), but that can have a severe economic impact on the farm. During this activity, a mass of information is supplied: indeed, the slaughterhouse plays the role of "epidemiological observatory", thanks to the fast observation of a huge number of animals from different farms and areas, and to the availability of complete information on the animals (e.g. origin, age, sex, breed, Food Chain Information, etc.). The registration and communication of the inspection outcomes is particularly useful in order to inform farmers about the health status of the herd and the main problems to be faced at farm level, favoring a preventive approach (Dailidaviciene et al., 2010; Knock and Carroll, 2019). This approach can lead to a classification of the farms based on the risk level, and allows to track the diffusion of infectious agents and parasites. With this aim, the previously cited EU Reg. 627/2019 supplies a model document for communication with the holding of provenance, to communicate every case of disease, welfare issue, or decision concerning meat. This important tool requires a careful identification, codification and registration of the outcomes of post mortem inspection.

The present study aimed to collect and analyze data obtained from the routine post mortem veterinary inspection of bovine livers performed in three abattoirs, located in two Italian regions characterized by different climate patterns and animal husbandry techniques; the prevalence of liver lesions 
Table 1. Composition of slaughtered animal population.

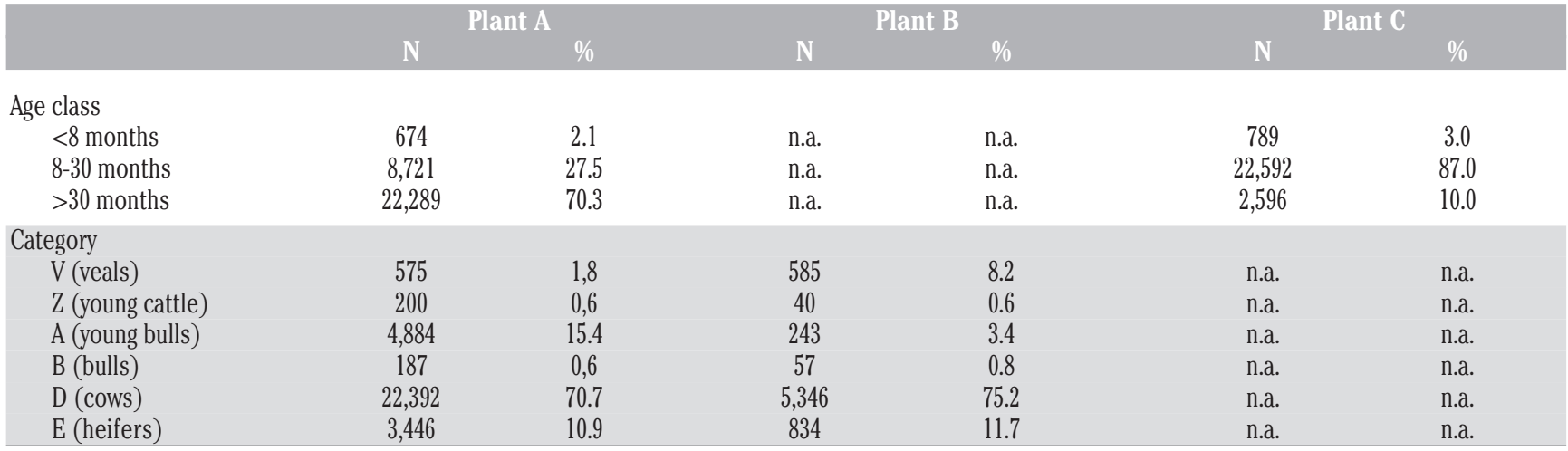

n.a.: information not available.

was combined with the available information concerning the slaughtered animals, thus highlighting the relative frequency of the different lesions based on animal age and category, season and geographical area.

\section{Materials and methods}

The data used for the study were obtained from three abattoirs (indicated as A, B and C) located in Lombardy (Northern Italy, plants A and B) and Puglia (Southern Italy, plant C). A total of 64,766 animals were subjected to post mortem inspection: 31,684 animals in plant A (years 20182019), 7,105 animals in plant B (year 2020) and 25,977 animals in plant $\mathrm{C}$ (years 20162019).

The available information about the composition of the population of slaughtered cattle is reported in Table 1. A clear difference between the plants located in Northern Italy (A and B) was evidenced, with a predominance of older animals (mainly milking cows at the end of their production period), and the plant located in Puglia, which population was mainly composed by animals aging 8-30 months (e.g. young bulls, heifers and young cows).

All the data were obtained from the reports produced by the official veterinarians by using excel sheets or dedicated softwares. The post mortem liver lesions were classified with the following denominations: a) steatosis; b) abscesses; c) distomatosis (fascioliasis or dicrocoeliosis); d) hydatidosis; e) fibrosis (including atrophy/cirrhosis); f) perihepatitis (adhesion); g) telangiectasis; h) other lesions.

For each animal, the following information was recorded, when available: slaughtering plant, slaughtering date (season), category and age class ( $<8$ months, $8-30$ months, $>30$ months).

The frequency of lesions was analyzed by chi-square test or (in the case of a limited

Table 2. Bovine liver lesions prevalence in the three slaughtering plants.

\begin{tabular}{lcc} 
& N condemned/total livers & Lesions prevalence (\%) \\
Plant A & $2,648 / 31,684$ & $8.4^{\mathrm{B}}$ \\
Plant B & $906 / 7,105$ & $12.8^{\mathrm{A}}$ \\
\hline Plant C & $1,652 / 25,977$ & $6.4^{\mathrm{C}}$ \\
Total & $5,206 / 64,766$ & 8.0 \\
\hline AB, C. Significant difference among the plants $(\mathrm{P}<0.01)$. &
\end{tabular}

Table 3. Prevalence of the specific liver lesions in the total animal population.

\begin{tabular}{lccc} 
Lesion & N condemned livers & \% (total animal population) & \% (total lesions) \\
Steatosis & 1,790 & 2.8 & 34.2 \\
Abscesses & 1,009 & 1.6 & 19.3 \\
\hline Distomatosis & 790 & 1.2 & 15.1 \\
Hydatidosis & 204 & 0.3 & 3.9 \\
\hline Fibrosis/cirrhosis & 135 & 0.2 & 2.6 \\
Perihepatitis & 678 & 1.0 & 12.9 \\
\hline Telangiectasis & 362 & 0.6 & 6.9 \\
Other lesions & 268 & 0.4 & 5.1 \\
\hline
\end{tabular}

number of data) Fisher's exact test; significance threshold was set at $\mathrm{P}<0.05$.

\section{Results}

\section{Frequency of liver lesions}

A total of 5,206 livers were condemned due to the presence of lesions, with a mean prevalence of $8.0 \%$ (Table 2). Significant differences were detected among the three plants, with a higher rate in plant $\mathrm{B}$ towards $\mathrm{A}$ and $\mathrm{C}(\mathrm{P}<0.01)$. These differences can be due to different factors, such as the different composition of animal population, a real difference between animals coming from different areas, or a different notification rate in the plants; these aspects were further deepened. The rate of detection of the specific liver lesions is shown in Table 3 . The most frequently detected lesion was steatosis (about $1 / 3$ of the total number of lesions detected), followed by abscesses, distomatosis and perihepatitis. The relative prevalence of these lesions was strongly influenced by the pattern of animal populations, as described below.

\section{Effect of animal age/category}

Considering animal age and category, a marked variability was observed (Figure 1): a significantly higher prevalence $(\mathrm{P}<0.01)$ was indeed detected in animals older than 30 months and specifically in cows, if compared with all the other categories. Significantly lower rates were observed in calves (aged $<30$ months, cat. V) and young cattle (max. 12 months), as expected.

A distribution of the main lesions within the age classes and categories is reported in Table 4. Data showed the marked influence of animal age on the frequency of steatosis, that was detected mainly in animals aged $>$ 30 months and in females (about half of the lesions detected in cows) $(\mathrm{P}<0.01)$, whereas a higher prevalence of abscesses was 
Table 4. Distribution of the main liver lesions among age classes and categories.

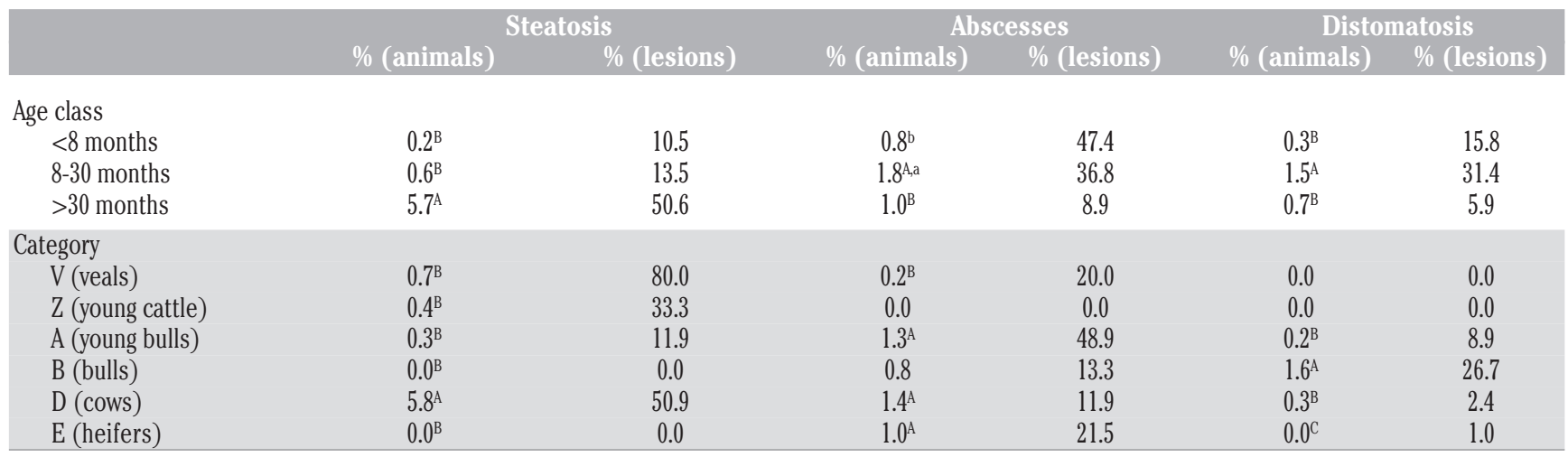

$\overline{A B, C}, \mathrm{Significant}$ difference among the age classes or categories $(\mathrm{P}<0.01)$. ${ }^{\mathrm{a}} \mathrm{bS}$ Significant difference among the age classes or categories $(\mathrm{P}<0.05)$.

observed in younger animals (mainly young bulls), with significantly lower rate in calves $(\mathrm{P}<0.01)$. Regarding distomatosis, the higher prevalence observed in young (830 months) animals was strongly influenced by the data obtained from plant $\mathrm{C}$, where this lesion was more frequently found. The importance of the high rate of some lesions (e.g. steatosis in calves or distomatosis in bulls) should be considered with care, as a limited number of animals belonging to these categories was slaughtered.

\section{Influence of the season}

The total prevalence of liver lesions varied through the seasons: higher values were recorded in summer $(9.8 \%)$ and autumn $(8.9 \%)$, whereas a decrease was observed in winter and spring (6.5-6.9\%). This general trend was influenced by the plant considered, as it was more marked in Northern Italy (and especially in plant A), where the animal population was dominated by cows. Indeed, the seasonal variability was mainly observed for steatosis (Figure 2 ), whereas no particular trends were observed for other lesions. Considering the rate of specific lesions on the total number of lesions detected, a higher value was observed in summer for steatosis, in winter for abscesses and in spring for distomatosis.

\section{Influence of geographical area}

Aiming to compare animals slaughtered in different Italian regions (as most slaughtered animals are reared in the same area where they are slaughtered, namely the Pianura Padana and Puglia), data belonging to the same age class but from different regions (plants A and C) were compared. The prevalence of the three main lesions is shown in Figure 3. A higher prevalence of steatosis $(\mathrm{P}<0.01)$ was clearly evidenced in animals slaughtered in plant A vs. C, especially in animals aged $>30$ months $(6.1 \%$ $v s$. less than 1\%). A specular picture regard-

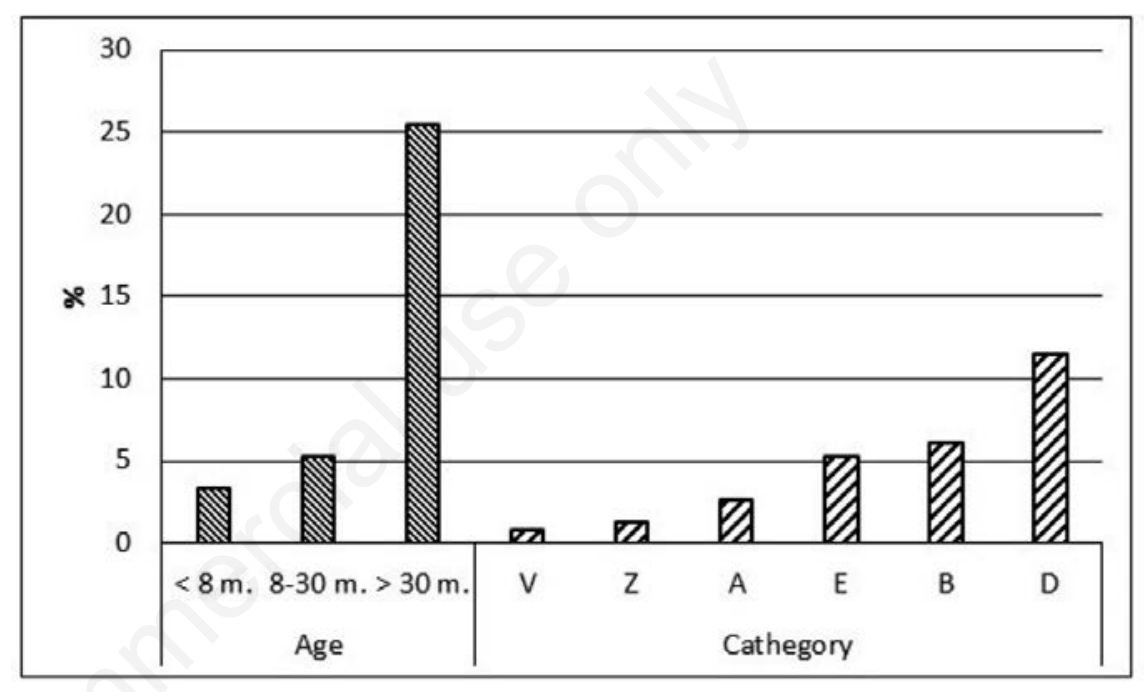

Figure 1. Liver lesion prevalence in different age classes and bovine categories.

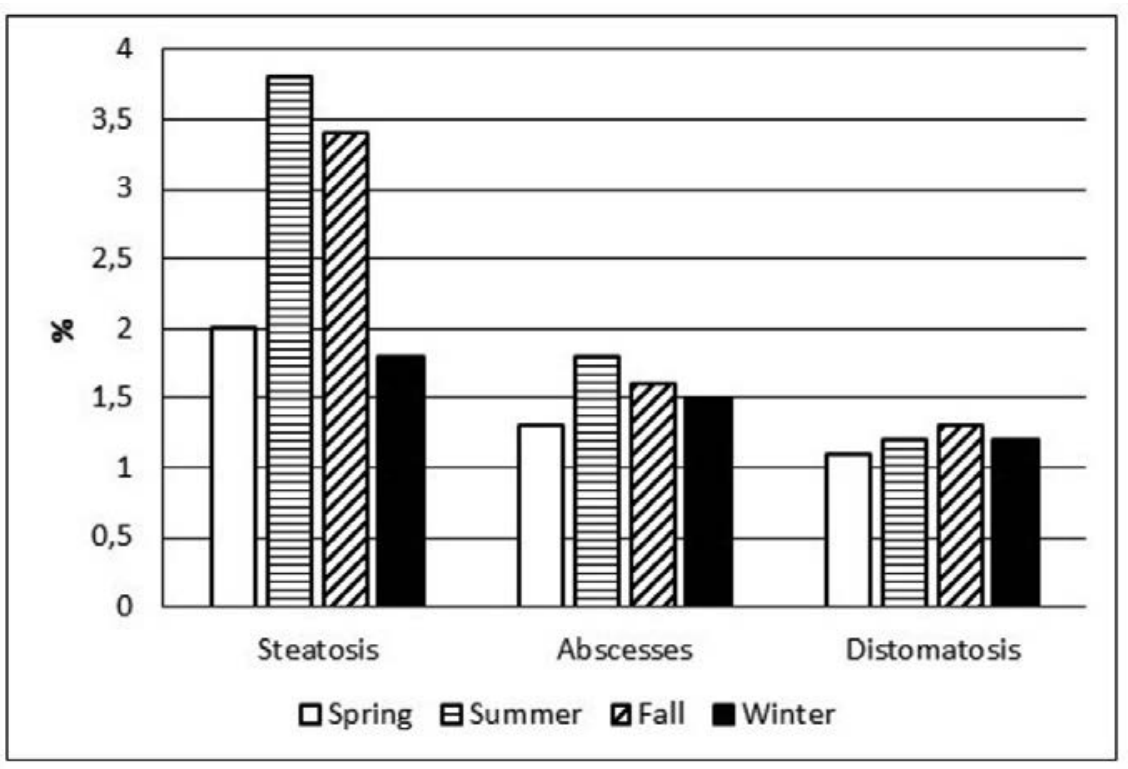

Figure 2. Seasonal variation in the detection rate of the three main liver lesions. 
ed distomatosis, with significantly higher rates $(\mathrm{P}<0.01)$ from plant $\mathrm{C}$ both in animals aged 8-30 months and more than 30 months.

\section{Detection rate in different plants}

In order to evaluate the possible difference in the notification rate due to a different registration system adopted in the plants, the data obtained from plants $\mathrm{A}$ and B were compared, considering the same category of animals (cows), in order to limit the influence of external factors. The results are shown in Figure 4. Some evident differences were observed, in particular for steatosis (higher in plant A), abscesses and perihepatitis (higher in plant $\mathrm{B})(\mathrm{P}<0.01)$.

\section{Discussion}

The results obtained from the liver post mortem examination of cattle from the three abattoirs considered in the study indicated a mean prevalence of $8 \%$ : this value is markedly lower if compared to those obtained by other authors, that is around 2025\% (Dailidavičienè et al., 2010; McKeith et al., 2012); this could be due to the difference between retrospective data on routine veterinary activity (registration of condemned livers) and specifically dedicated experimental studies (registration of any lesion, independently from the judgement). A higher liver lesion prevalence was observed in older animals, and in particular in cows. This was expected, as older animals have more occasion of experiencing infections, parasitic diseases, or dysfunctions due to stressful events: considering milking cows, the post partum period is extremely stressful, and this status can determine the end of their productive life and subsequent destination to slaughtering (Dupuy et al., 2013).

The most diffused lesion was steatosis, representing about $1 / 3$ liver lesions; the overall prevalence $(2.8 \%)$ was similar to that observed in a previous study (Rezac et al., 2014). A marked difference was shown by comparing animal categories and age classes: in fact, it represented about half of the lesions detected in animals aging more than 30 months (cows). It is a typical dysfunction of the post partum and early lactation period, owing to an energy deficiency and subsequent lipomobilization: previous studies already shown a very high frequency (more than $50 \%$ ) in the first month of lactation (Djokovic et al., 2011).

Abscesses were the second prevalent lesion: the rate observed $(1.6 \%)$ was low; literature data indicate an extreme variability of the frequency of liver abscesses (5-
30\%: Brink et al., 1990; Habarugira et al., 2016; McKeith et al., 2012; Rezac et al., 2014). The onset of this lesion is mainly influenced by animal feeding practices: the relative deficiency of fiber in animal feeding predisposes to ruminal acidosis, and consequently to ruminitis and to the diffusion of bacteria via the portal vein (Brink et al., 1990; Nagaraja e Chengappa, 1998). This situation is particularly frequent in feedlot cattle; in our study, it represented almost half of the lesions in young bulls, that were the most exposed animals: such picture could be linked to a faster growth rate of these animals (Deehan et al., 1995; Nagaraja et al., 1996). The detection of abscesses in milking cows $(12 \%$ in these study) could be due to increased feed inges- tion and feed changes in the pregnancy and lactation phases (Nagaraja, 2000; Doré et al., 2007).

Distomatosis showed an average prevalence of $1.6 \%$, considering both the lesions caused by Fasciola hepatica or Dicrocoelium dendriticum. Literature data indicate an extremely variable prevalence (0.12-86\% in Europe); a previous collection of data indicated a mean prevalence of $11.1 \%$ in Italian slaughtered cattle (Meehmod et al., 2017). These diseases are linked to pasture grazing and can be detected in all the animal categories: considering cows and heifers, grazing is the main feeding source in some areas where traditional farming is more diffused. On the other hand, young bulls are bred without grazing

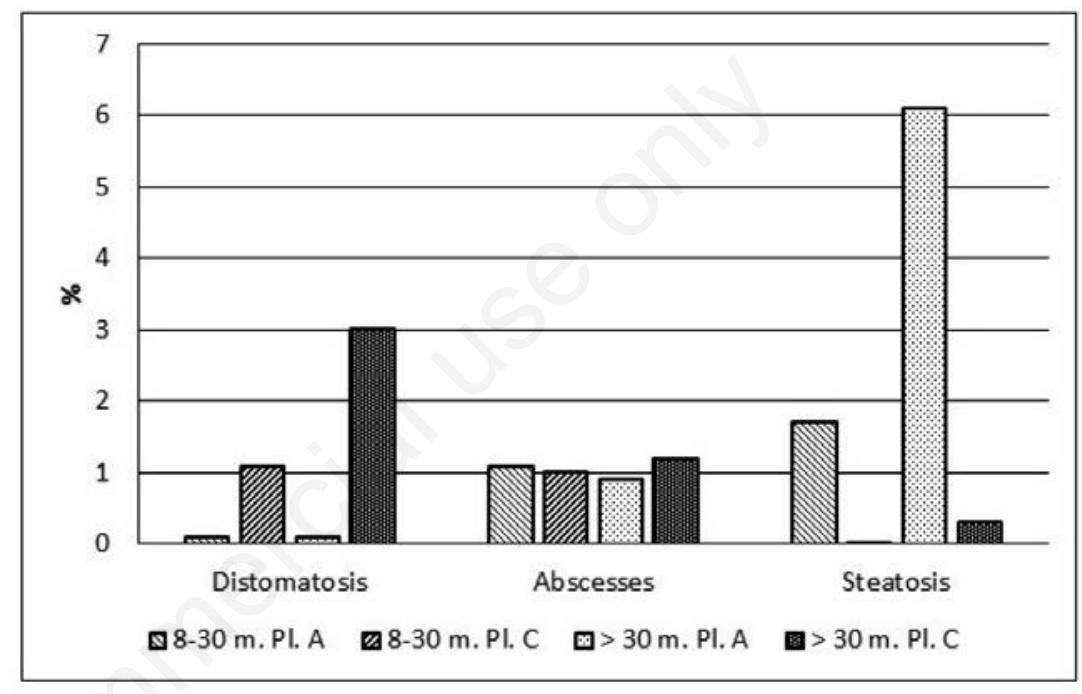

Figure 3. Prevalence of the main liver lesions - Comparison between geographical areas.

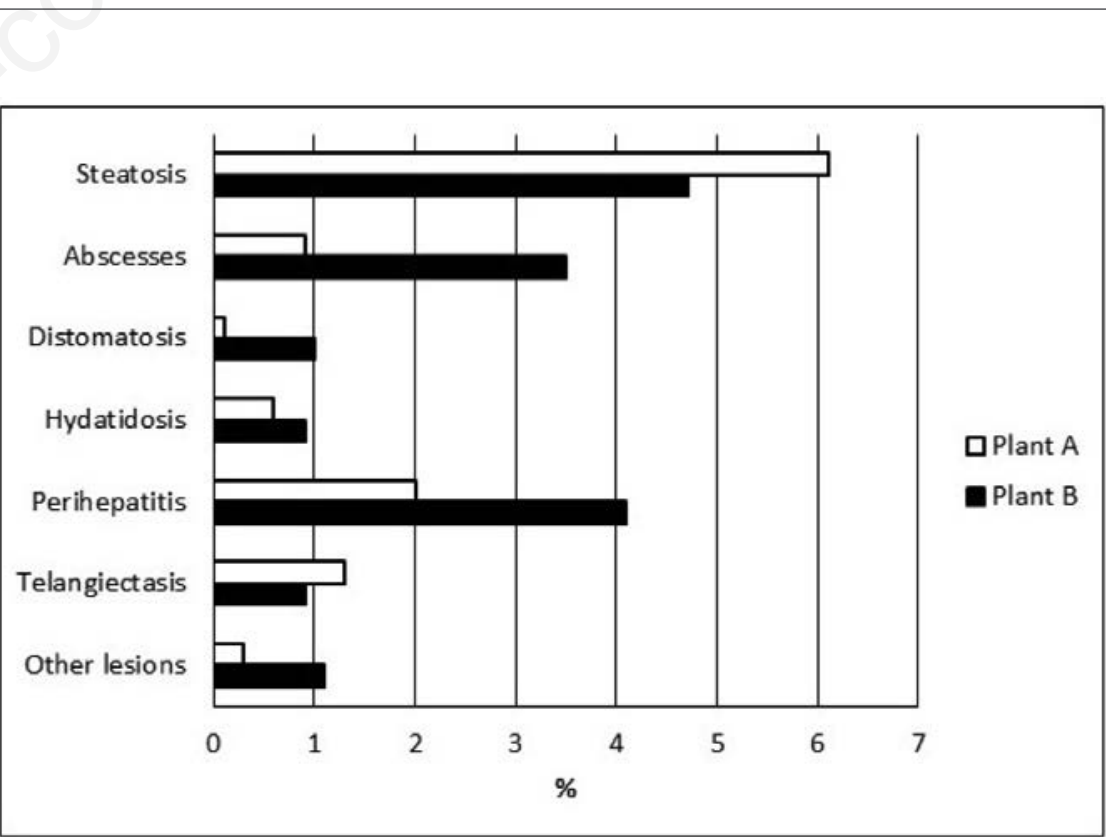

Figure 4. Prevalence of the specific liver lesions in cows slaughtered in plants A and B. 
during the last pre-slaughter period, but it has to be noted that grazing is usual in the previous phases, and the presence of liver flukes is often a chronic situation, lasting for several months.

The slaughtering season had a moderate impact on liver lesion prevalence: in the warmer period (summer and early autumn) a higher prevalence was observed, but this result was mainly due to steatosis in cows: this result was expected, as higher temperatures constitute an additional stressful factor, especially in the post partum/early lactation period.

The comparison among the two geographical areas showed a very evident difference, mainly due to different farming systems: in Northern Italy, where animal population is mainly composed by intensively reared animals, and in particular by milking cows, steatosis was by far the main lesion detected, whereas distomatosis was markedly prevalent in cattle slaughtered in Southern Italy, where more traditional rearing and feeding practices are usually applied.

Finally, the data obtained from plants A and B on similar animal populations (cows) were compared, showing some differences in the detection rate: this result could be due to casual variability, but it could also be influenced by a lack of common registration guidelines, especially for mild lesions, among different plants.

\section{Conclusions}

The results of this study highlight the importance of combining data from post mortem inspection with the available information on the animals, to supply a correct feedback to farmers about the diseases and dysfunctions that are influenced by management and feeding practices. The role of the slaughterhouse as epidemiological observatory is widely acknowledged and adopted by the current legislation, highlighting the need for registration and communication of diseases and animal welfare impairment. Indeed, a model for the communication to the farmer of ante mortem and post mortem inspection outcomes, already reported in the repealed EU Reg. $2074 / 2005$, is now included in the current EU Reg. 627/2019. This tool could be useful to apply a preventive approach at farm, and allows to get a proper feedback to the slaughterhouse by the use of Food Chain Information accompanying the further animal lots. Moreover, the simplification of post mortem procedures for cattle set by the EU Reg. 627/2019, prescribing only a visual inspection in absence of particular con- cerns, requires a particular care in the detection, identification and registration of lesions. In this light, any tool facilitating a homogenous approach can give a useful support to official veterinarians.

\section{References}

Brink DR, Lowry SR, Parrott JC, Stock R, 1990. Severity of liver abscesses and efficiency of feed utilization of feedlot cattle. J Anim Sci 68:1201-7.

Brown TR, Lawrence TE, 2010. Association of liver abnormalities with carcass grading performance and value. J Anim Sci 88:4037-43.

Dailidavičienè J, Januškevičienè G, Juozaitienè V, Paulauskas V, 2010. Analysis of pathologic lesions in the livestock and poultry slaughtered in the meat establishments of Lithuania. Veterinarija ir Zootechnika 52:33-42.

Dehaan LL, Rick SC, Fahey GC, Gibson ML, 1995. The effect of age, background and gender on feed intake by feedlot cattle. Symposium: Intake by feedlot cattle, pp. 9-22.

Djokovic R, Ilic Z, Kurcubic V, Petrovic M, Doskovic V, 2011 Functional and morphological state of the liver in Simmental dairy cows during transitional period. Rev Med Vet-Touluse 162:574-9.

Doré E, Fecteau G, Hélie P, Francoz D, 2007. Liver abscesses in Holstein dairy cattle: 18 cases (1992-2003). J Vet Intern Med 21:853-6.

Dupuy C, Morignat E, Maugey X, Vinard JL, Hendrikx P, Ducrot C, Calavas D, Gay E, 2013. Defining syndromes using cattle meat inspection data for syndromic surveillance purposes: a statistical approach with the 2005-2010 data from ten French slaughterhouses. BMC Vet Res 9:88.

EU - European Union, 2005. Commission Regulation (EC) No 2074/2005 of 5 December 2005 laying down implementing measures for certain products under Regulation (EC) No 853/2004 of the European Parliament and of the Council and for the organisation of official controls under Regulation (EC) No $854 / 2004$ of the European Parliament and of the Council and Regulation (EC) No $882 / 2004$ of the European Parliament and of the Council, derogating from Regulation (EC) No 852/2004 of the European Parliament and of the Council and amending Regulations (EC) No 853/2004 and (EC) No 854/2004. OJ L338:27-59, 22-12-2005.

EU - European Union, 2019. Commission implementing Regulation (EU) 2019/627 of 15 March 2019 laying down uniform practical arrangements for the performance of official controls on products of animal origin intended for human consumption in accordance with Regulation (EU) 2017/625 of the European Parliament and of the Council and amending Commission Regulation (EC) No 2074/2005 as regards official controls. OJ L131:51-100, 17-5-2019.

Habarugira G, Mbasinga G, Mushonga B, Teedzai C, Kandiwa E, Ojok L, 2016. Pathological findings of condemned bovine liver specimens and associated economic loss at Nyabugogo abattoir, Kigali, Rwanda. Acta Trop 164:27-32.

Khan MK, Sajid MS, Khan MN, Iqbal Z, Iqbal MU, 2009. Bovine fasciolosis: prevalence, effects of treatment on productivity and cost benefit analysis in five districts of Punjab, Pakistan. Res Vet Sci 87:70-5.

Knock M, Carroll GA, 2019. The potential of post-mortem carcass assessments in reflecting the welfare of beef and dairy cattle. Animals 9:959.

McKeith RO, Gray GD, Hale DS, Kerth CR, Griffin DB, Savell JW, Raines CR, Belk KE, Woerner DR, Tatum JD, Igo JL, VanOverbeke DL, Mafi GG, Lawrence TE, Delmore RJ Jr, Christensen LM, Shackleford SD, King DA, Wheeler TL, Meadows LR, O'Connor ME, 2012. National beef quality audit-2011: Harvestfloor assessments of targeted characteristics that affect quality and value of cattle, carcasses, and byproducts. J Anim Sci 90:5135-42.

Mehmood K, Zhang H, Sabir AJ, Abbas RZ, Ijaz M, Durrani AZ, Saleem MH, Rehman MU, Iqbal MK, Wang Y, Ahmad HI, Abbas T, Hussain R, Ghori MT, Ali S, Khan AU, Li J, 2017. A review on epidemiology, global prevalence and economical losses of fasciolosis in ruminants. Microb Pathogenesis 109:253-62.

Montanholi YR, Haas LS, Swanson KC, Coomber BL, Yamashiro S, Miller SP, 2017. Liver morphometrics and metabolic blood profile across divergent phenotypes for feed efficiency in the bovine. Acta Vet Scand 59:24.

Nagaraja TG, 2000. Liver abscesses in beef cattle: Potential for dairy monitoring? Proceedings of the American Association of Bovine Practitioners 33:65-8.

Nagaraja TG, Chengappa MM, 1998. Liver abscesses in feedlot cattle: a review. J Anim Sci 76:287-98.

Nagaraja TG, Laudert SB, Parrott JC, 1996. 
Liver abscesses in feedlot cattle. Part 2. Incidence, economic importance and prevention. Comp Cont Educ Pract 18:S264-73.

Rezac DJ, Thomson DU, Siemens MG, Prouty FL, Reinhardt CD, Bartle SJ, 2014. A survey of gross pathologic conditions in cull cows at slaughter in the
Great Lakes region of the United States. J Dairy Sci 97:4227-35.

Schweizer G, Braun U, Deplazes P, Torgerson PR, 2005. Estimating the financial losses due to bovine fasciolosis in Switzerland. Vet Rec 157:188-93.

Stärk KDC, Alonso S, Dadios N, Dupuy C, Ellerbroek L, Georgiev M, Hardstaff J,
Huneau-Salaün A, Laugier C, Mateus A, Nigsch A, Afonso A, Lindberg A., 2014. Strengths and weaknesses of meat inspection as a contribution to animal health and welfare surveillance. Food Control 39:154-62. 